\title{
Physical fitness in morbidly obese patients: effect of gastric bypass surgery and exercise training.
}

Stegen Sanne ${ }^{1,2,3}$, Derave Wim ${ }^{1}$, Calders Patrick ${ }^{2}$, Van Laethem Christophe ${ }^{2}$ and Pattyn Piet ${ }^{3}$

\section{Affiliations:}

1. Department Movement and Sport Sciences, Ghent University, Watersportlaan 2, 9000 Ghent, Belgium (Europe)

2. Department Rehabilitation Sciences and Physiotherapy, Ghent University, De Pintelaan 185, 9000 Ghent, Belgium (Europe)

3. Department of Surgery, Ghent University and University Hospital Ghent, De Pintelaan 185, 9000 Ghent, Belgium (Europe)

\section{Corresponding Author: Stegen Sanne}

E-mail address: sanne.stegen@ugent.be

Telephone: 0032485507082 or 003292648631

Fax numbers: 003292646484

Short title (max 30 characters): Gastric Bypass and Exercise 


\section{ABSTRACT}

\section{Background:}

There is a growing consensus that bariatric surgery is currently the most efficacious and long-term treatment for clinically severe obesity. However, it remains to be determined whether poor physical fitness, an important characteristic of these patients, improves as well.

The purpose of this pilot study is to investigate the effect of gastric bypass surgery on physical fitness and to determine if an exercise program in the first four months is beneficial.

\section{Methods:}

Fifteen morbidly obese patients (BMI: $43,0 \mathrm{~kg} / \mathrm{m}^{2}$ ) were tested before and 4 months after gastric bypass surgery. Eight of them followed a combined endurance and strength training program. Before and 4 months after the operation anthropometrical characteristics were measured and an extensive assessment of physical fitness (strength, aerobic and functional capacity) was performed.

\section{Results:}

Large scale weight loss through gastric bypass surgery results in a decrease in dynamic and static muscle strength and no improvement of aerobic capacity. In contrast an intensive exercise program could prevent the decrease and even induced an increase in strength of most muscle groups. Together with an improvement in aerobic capacity, functional capacity increased significantly. Both groups evolved equally with regard to body composition (decrease in fat mass and fat-free mass).

\section{Conclusions:}

An exercise training program in the first 4 months after bariatric surgery is effective and should be promoted, considering the fact that physical fitness does not improve by weight loss only.

\section{Key words:}

Gastric bypass, bariatric surgery, morbidly obese, exercise, physical fitness, strength, functional capacity, endurance, fat-free mass, weight loss 


\section{INTRODUCTION}

The number of bariatric surgery procedures has increased significantly over the past few decades, not only in the United States, but also worldwide [1]. Two major reasons can be defined. First, the prevalence of morbidly obesity increases rapidly, approaching $8 \%$ for some populations in the United States [2]. Secondly, there is a growing consensus that bariatric surgery is currently the most efficacious and long-term treatment for clinically severe obesity, accompanied with a low mortality rate [3-5]. Morbid obesity is associated with a number of comorbidities such as hypertension, dyslipidemia, type 2 diabetes or insulin resistance, sleep apnea, etc [6-8]. In addition to fat mass reduction, bariatric surgery has pronounced effects on these co-morbidities [3,9], even before weight loss occurs $[10,11]$.

However, it remains to be determined whether poor physical fitness, a key factor in the vicious circle of obesity and physical inactivity [12] and an important characteristic of morbidly obese patients $[13,14]$, improves as well after bariatric surgery. There are some reasons to assume that this is not selfevident. To answer this question we must keep in mind that physical fitness is a broad concept that covers muscle strength but also functional and aerobic capacity. First of all, we do know that large scale weight loss always results in a decrease in fat-free mass (FFM). Carey et al. [15] reported that FFM loss accounts for $30-35 \%$ of the total weight loss over the first six months as a consequence of Roux-en-Y Gastric bypass. We can presume that the high amount of weight loss, the malabsorptive characteristic of the procedure and an inadequate protein intake [16] induces this skeletal muscle atrophy, with a concomitant decrease in muscle strength. Muscle strength is an important aspect of functional capacity, e.g. knee extensor muscle strength has been associated with gait speed, stair climbing, getting up from a seated position, postural stability and even to the occurrence of falls in a number of investigations [17,18]. Maffiuletti et al. [19,20] indicated the importance of a decreased relative knee extensor muscle strength in terms of body weight in obese patients, by contributing to reduced functional capacity during daily living activities. Until today, only 2 articles have been published to evaluate changes in functional capacity following bariatric surgery. A prospective 1-year study by Maniscalco et al. [21] showed an improvement of the distance walked in six minutes (6MWD) from 475.7 to 626.3 meters in 15 female morbidly obese patients 1 year after laparoscopic adjustable gastric banding. Tompkins J et al. [22] confirmed these results and added normative values, 
namely presurgical walking distance was $55 \%$ of normative values and improved up to $75 \%$ six months after the operation. Both studies conclude that functional capacity improves because the six minute walking distance improves. The main reason is that less adipose tissue around the legs is more mechanical efficient, which makes walking less exhausting. Additionally, they suggest that aerobic capacity improves as well. However, we believe that this is partly true. Poor aerobic fitness in morbidly obese subjects is explained by both reduced cardiovascular function [23] as well as a low oxidative capacity of skeletal muscle [24-26]. Indeed, weight loss ameliorates cardiovascular function, but this cannot be adopted for the oxidative capacity of the obese muscle. It is known that weight loss alone, accomplished by low calorie diets, does not improve mitochondrial content and electron chain transport activity in skeletal muscle of sedentary obese subjects [27], it even decreases mitochondrial size. Further, a high proportion of fast glycolytic type II muscle fibers and thus a low portion of oxidative type I muscle fibers is characteristic for the obese muscle [28]. Again, weight loss alone cannot change skeletal muscle fiber type. Therefore, there is no reason to assume that the extreme poor aerobic capacity will improve by gastric bypass surgery alone.

A first goal of the present study is to investigate the effect of gastric bypass surgery on physical fitness with a many-sided physical performance battery (muscle strength, aerobic and functional capacity). An additional goal of this study is to examine the feasibility and effectiveness of an exercise program in morbidly obese patients after gastric bypass surgery. To our knowledge, no studies have been reported that examine the effect of aerobic and resistance exercise in the period following bariatric surgery. Rice et al. [29] and Janssen et al. [30] reported that a low calorie diet (energy deficit of 1000 $\mathrm{kcal} / \mathrm{d}$ ) combined with either aerobic exercise or resistance exercise results in respectively an increased aerobic capacity (VO2 max) and muscle strength in lower and upper body. The diet group without exercise had no amelioration in aerobic capacity nor in muscle strength, furthermore a significant loss of FFM was present, while not in the exercise groups. It remains to be determined whether these data on low calorie diets can be extrapolated toward the first post-operative period following gastric bypass surgery. We therefore hypothesize that exercise training during the months following a gastric bypass procedure can improve aerobic capacity and prevent the decline in muscle mass and muscle strength, with implications to functional impairment. 


\section{MATERIALS AND METHODS}

\section{$\underline{\text { Subjects }}$}

Nineteen gastric bypass patients were recruited for the study after checking the exclusion and inclusion criteria. Exclusion criteria were diabetes, severe cardio-vascular diseases and exerciselimiting co-morbidities such as musculoskeletal impairments. To be included, patients must undergo gastric bypass surgery, a mixed restrictive and malabsorptive form of bariatric surgery. Also conversions from a gastric banding to a gastric bypass procedure were allowed. The subjects gave their informed consent, and the study was approved by the local Ethics Committee (Ghent University Hospital, Ghent, Belgium).

All patients were able to make the choice between the intervention group (exercise program after gastric bypass 'GB+E', 'the trained patients') or the control group (only gastric bypass 'GB', 'the untrained patients'). There was a drop-out of four patients ( 2 of GB and 2 of GB+E), so that finally fifteen morbidly obese patients (BMI: 42,5 $\pm 6,6 \mathrm{~kg} / \mathrm{m}^{2}$, age: $40,5 \pm 8$,1years, 4 men and 11 women) finished the study, of which 7 patients in 'GB' and 8 patients in 'GB+E'. The characteristics of the groups are shown in table 1.

Reasons of refusal were domicile distance and a demanding job and household. Reasons of drop-out were also a demanding job, household or education.

\section{$\underline{\text { Study protocol }}$}

Both the patients of 'GB' and 'GB+E' underwent the same measurements before and four months after the operation. Only the patients of 'GB+E' started one month after the operation with an exercise program during 3 months.

\section{EXERCISE PROGRAM}

The patients in group 'GB+E' exercised three times a week during 12 weeks (36 sessions). Each training session lasted 75 minutes and included 10 minutes of cardiovascular warming up, 25 minutes of strength training, 30 minutes of endurance training and a cooling-down period of 10 minutes. 
During each session, patients were individually guided and supervised by Masters in Movement and Rehabilitation Sciences.

Strength exercises were performed using stack-weight equipment (elbow flexion and extension and knee flexion and extension). Intensity of strength training was calculated from 1 repetition maximum (1RM)-values. The starting level was $60 \%$ of $1 \mathrm{RM}$, which increased up to $75 \%$ of $1 \mathrm{RM}$. Patients were habituated to the exercises and equipment during the first 3 training sessions. The next 15 sessions, 2 sets of 15 repetitions at $60 \%$ of $1 \mathrm{RM}$ was done. In the final 18 sessions, 3 sets of 10 repetitions at $75 \%$ was done. Resting periods between repetition sets was approximately 60 seconds.

Endurance training consisted of cycling (10 min), walking (10 min) and stepping (10 min). Exercise intensity was initially set at $60 \%$ of heart rate reserve (HRR, defined as the difference between resting heart rate and peak heart rate) and was gradually increased up to $75 \%$ of HRR at the end of the training period. Stationary bicycles, treadmills and steppers were used in a rehabilitation training room of the University Hospital of Ghent (Belgium). During the training sessions, heart rate was monitored by Polar Heart Watches.

\section{MEASUREMENTS}

1. Anthropometric variables and Body composition

Body Mass Index or BMI (weight/ height ${ }^{2}$ ) and waist circumference (at the level of the biggest circumference, near the umbilicus) were determined using a digital balance scale, a stadiometer and a tape meter. Body composition was assessed by bio-impedance (Bodystat 1500 MDD; Bodystat Ltd, Douglas, Isle of Man, UK). Patients were in supine position for at least 5 minutes. Surface electrodes were attached to the right hand (red lead: behind the knuckle of the middle finger; black lead: on the wrist to the ulnar head) and foot (red lead: behind the $2^{\text {nd }}$ toe next to the big toe; black lead: On the ankle at the level of and between the medial and lateral malleoli). Total body water (TBW) was calculated from the measured impedance using the following gender specific formula: females: TBW=0.382x $\left(\right.$ height $^{2} /$ impedance $)+0.105 x$ bodyweight +8.315 and men: 
TBW $=0.396^{*}\left(\right.$ height $^{2} /$ impedance $)+0.143$ xbodyweight +8.399 [31]. Fat-free mass (FFM) was then calculated from the TBW by assuming 73.2\% hydration of FFM: FFM=TBW/0.732 [32]. Body fat mass (FM) was calculated using a two compartment model: body weight=FFM + FM.

2. Physical fitness test battery

a. Dynamic muscle strength:

One Repetition Maximum (1RM) was determined unilaterally with the indirect Holtenmethod using commercially available stack weight and fitness equipment for biceps, triceps, quadriceps and hamstrings. For each patient a test weight was defined so that patients would be able to achieve maximal 6 to 12 repetitions. From this number of repetitions the 1RM was calculated using the Holten diagram. The Holten diagram relates the number of repetitions to the percentage of maximum strength. The global score $(\mathrm{kg})$ for the biceps, triceps, quadriceps and hamstrings exercise was calculated by taking the sum of the right and left arm or leg.

b. Static muscle strength

Static muscle strength was evaluated by measuring the handgrip strength with a handgrip dynamometer (JAMAR). Subjects were standing in the anatomical position, with the arm flexed at $90^{\circ}$, without touching the body. The participant was asked to squeeze as hard as possible. Three trials were made with a pause of about 10-20 seconds between each trial to avoid the effects of muscle fatigue. Left and right hand were alternated. The best score (in $\mathrm{kg}$ ) was registered.

\section{c. Muscle fatigue}

The participant was in the same position as described in 'b. static muscle strength'. He/she had to squeeze the dynamometer with the strongest hand (determined in b.) with as much force as possible and as long as possible. The test was finished when grip strength dropped to $50 \%$ of its maximum during sustained contraction. The seconds were registered. 


\section{d. Functional capacity}

- $\quad$ Sit-to-stand test

This test measured the maximum number of times that a patient could rise to a full stand from a seated position within 30 seconds, without pushing off with the arms. The number of completed stands (up-down) was considered the patient's score. This assessment has high test-retest reliability.

- Six-minute walk distance (6MWD)

All patients performed a standardized, self-paced 6 MWT in a 20-meter long corridor. They were instructed to cover as much distance as possible within 6 minutes without running. Patients were allowed to stop at every moment of the test, but were encouraged to restart as soon as possible. During the test, patients were instructed as described by Enright et al. [33]. Covered distance after 6 minutes was measured to the nearest meter. Heart rates were monitored during the test by Polar Heart Watches.

e. Maximal cardiopulmonary exercise test

Patients performed a maximal cardiopulmonary bicycle test on a cyclo-ergometer (Gymna). A gradual protocol was used, starting at 30 watt with gradual increase of 15 watts every minute, with the subjects cycling at 60-70 rotations per minute. Patients continued cycling until self-determined limits of their functional capacities or until the physician stopped the test because of potentially threatening symptoms. After the patients reached their maximum, subjects cycled during 3 minutes for active recovery at 1/3 of their maximal work load. Heart rates were continuously determined by electrocardiogram, whereas blood pressure was measured with a manual sphygmomanometer every two minutes. During the test, gas exchange was measured continuously using a portable mixing chamber system (MetaLyzer II, Cortex, Leipzig, Germany). The oxygen consumption $\left(\mathrm{VO}_{2}\right)$, carbon dioxide production $\left(\mathrm{VCO}_{2}\right)$, minute ventilation (VE) and respiratory exchange ratio (RER) were registered every 30 seconds. Peak $\mathrm{VO}_{2}$ is determined as the highest attained $\mathrm{VO}_{2}$ over 30 seconds during the 
test and expressed in both absolute values (peak $\mathrm{VO}_{2}, \mathrm{ml} / \mathrm{min}$ ), relative to body weight (peak $\mathrm{VO}_{2} / \mathrm{kgBW}, \mathrm{ml} / \mathrm{kg} / \mathrm{min}$ ) and relative to fat-free mass (peak $\mathrm{VO}_{2} / \mathrm{kgFFM}, \mathrm{ml} / \mathrm{kg} / \mathrm{min}$ ). The ventilatory equivalent method was used to determine the ventilatory anaerobic threshold (VAT), described by Wasserman K. [34]. This is based on the principle that ventilation increases promptly at the anaerobic threshold in proportion to the increase in $\mathrm{CO}_{2}$ produced from $\mathrm{HCO}_{3}{ }^{-}$buffering of lactic acid. This results in an increase in the ventilatory equivalent for $\mathrm{O}_{2}\left(\mathrm{VE} / \mathrm{VO}_{2}\right)$ without an increase in the ventilatory equivalent for $\mathrm{CO}_{2}\left(\mathrm{VE} / \mathrm{VCO}_{2}\right)$. The time of occurrence (seconds) of VAT, together with the workload (power output) and oxygen uptake at that moment are registered.

\section{$\underline{\text { Statistical analyses }}$}

Interaction and time effects were evaluated using a repeated-measures analysis of variance (ANOVA). To evaluate time effects within groups, paired t-tests were performed. Data are expressed as mean $( \pm$ standard deviation) and are analyzed with a commercially available statistical software program (SPSS 16.0, SPSS Inc, Chicago, Illinois, USA). Data are significant when $\mathrm{p}<0,05$. 


\section{RESULTS}

Anthropometric variables and body composition pre- and 4 months postoperative (Table 2).

The trained patients $(\mathrm{GB}+\mathrm{E})$ as well as the untrained patients $(\mathrm{GB})$ had the same decrease in weight $(\mathrm{GB}:-26,6 \pm 14,6 \mathrm{~kg} ; \mathrm{GB}+\mathrm{E}:-22,7 \pm 5,7 \mathrm{~kg}), \mathrm{BMI}\left(\mathrm{GB}:-8,3 \pm 4,1 \mathrm{~kg} / \mathrm{m}^{2} ; \mathrm{GB}:-8,1 \pm 2,5 \mathrm{~kg} / \mathrm{m}^{2}\right)$ and waist circumference (GB: $-20,3 \pm 11,6 \mathrm{~cm}$; GB+E: $-17,2 \pm 8,1 \mathrm{~cm}$ ). Weight loss resulted largely from significant decrease in fat mass (GB: $-19,0 \pm 10,2 \mathrm{~kg}$; GB+E: $-17,3 \pm 4,6 \mathrm{~kg}$ ), but also fat free mass (GB: - 7,6 \pm 4,7 kg; GB+E: 5,4 $\pm 2,6 \mathrm{~kg}$ ) decreased significantly four months after the gastric bypass operation. No interaction effects were found.

\section{Results of the physical fitness test battery (table 3)}

\section{MUSCLE STRENGTH}

The untrained patients (GB) had a pronounced decrease in Dynamic Muscle strength four months after the operation. They lost $16 \%$ of their quadriceps strength, $36 \%$ of their biceps strength and $39 \%$ of their triceps strength. By contrast, an exercise program (strength + endurance) could prevent this decrease concerning biceps strength (Pre: $21,8 \pm 8,0 \mathrm{~kg}$; Post: 25,9 $\pm 13,0 \mathrm{~kg}$ ) and triceps strength (24,3 $\pm 10,1 \mathrm{~kg}$; Post: $30,7 \pm 23,0 \mathrm{~kg})$ and even increased quadriceps strength with $72 \%$ and hamstrings strength with $27 \%$.

Static muscle strength, measured as handgrip strength, decreased in both GB and GB+E four months after gastric bypass surgery, respectively with $18 \%$ and $7 \%$. No interaction effects could be reported. Muscle fatigue, also measured with the handgrip dynamometer, was not influenced by gastric bypass surgery, nor by an additional exercise program.

\section{FUNCTIONAL CAPACITY}

Patients were also subjected to two tests that evaluated functional capacity. There was a tendency for an interaction effect concerning the sit-to-stand test $(\mathrm{p}=0,08)$. The trained patients $(\mathrm{GB}+\mathrm{E})$ improved their number of times to rise to a full stand from a seated position within 30 seconds (Pre: $13 \pm 3$ times to Post: $16 \pm 4$ times; $\mathrm{p}=0,045$ ), whereas the untrained patients $(\mathrm{GB})$ did not (Pre: $15 \pm 4$ times to Post: 
$15 \pm 3$ times; $\mathrm{p}=0,862$ ). The six minute walk distance, another important test that evaluates functional capacity, improved for both groups together. Further analyzes showed us that the increase in the $6 \mathrm{MWD}$ is mainly attributed to the increase in the training intervention group, namely GB+E: $+52 \pm$ $30 \mathrm{~m}$ and GB: $+30 \pm 68 \mathrm{~m}$. The heart frequency on the end of the 6MWD declined significantly for both groups.

\section{(MAXIMAL) AEROBIC CAPACITY}

In the maximal bicycle ergometer test, before the operation both groups reached their ventilatory anaerobic threshold (VAT) at the power (GB: $93 \pm 24$ watt; GB+E: $90 \pm 24$ watt) with an equal time of occurrence (GB: $270 \pm 107 \mathrm{sec}$; GB+E: $266 \pm 133 \mathrm{sec}$ ). Gastric bypass surgery, with a weight loss of average $25 \mathrm{~kg}$ after 4 months, did not improve time of occurrence of VAT and power at VAT. However, when patients followed an exercise program $(\mathrm{GB}+\mathrm{E})$ they could delay the time of occurrence of VAT (time of occurrence of VAT: $349 \pm 149 \mathrm{sec}$ ) (figure 1). To conclude, $\% \mathrm{VO}_{2}$ at $\mathrm{VAT} / \mathrm{VO}_{2}$ peak (the percentage oxygen uptake at VAT relative to the oxygen uptake at peak, also a measurement to define aerobic capacity in relation to total exercise capacity) revealed an interaction effect, meaning that both groups evolved differently considering exercise versus no exercise (table 4). Also peak exercise capacity parameters were recorded. Pre-operatively, the morbidly obese subjects reached a peak oxygen uptake of 17,4 $\pm 4,9 \mathrm{ml} / \mathrm{kg} / \mathrm{min}(\mathrm{GB})$ and 17,6 $\pm 3,2 \mathrm{ml} / \mathrm{kg} / \mathrm{min}(\mathrm{GB}+\mathrm{E})$, which can be defined as an extreme poor physical fitness $(<23 \mathrm{ml} / \mathrm{kg} / \mathrm{min})$. Surprisingly, absolute peak oxygen uptake $(\mathrm{ml} / \mathrm{min})$ and power (watt) were not improved 4 months after an intensive training program, nor by bariatric surgery. When expressed relative to body weight, peak oxygen uptake and peak power increased in both groups, however peak oxygen uptake relative to fat-free mass remained unchanged (table 5). 


\section{DISCUSSION}

\section{MUSCLE STRENGTH AND MUSCLE MASS}

The present study indicates that gastric bypass surgery results in a considerable decrease in dynamic muscle strength four months after the operation (-16\% of quadriceps strength, $-36 \%$ of biceps strength, $-39 \%$ of triceps strength). The most plausible explanation can be found in the decrease in muscle mass. The untrained patients (GB) lost $7.6 \mathrm{~kg}$ muscle mass, which is $29.7 \%$ of total body weight loss (- 26.6 kg). Two extensive reviews have been published by Stiegler et al. [35] and Chaston TB et al. [36] that confirm the positive relationship between weight loss and fat-free mass loss (FFML). Moreover, very low caloric diets result in greater FFML compared to low caloric diets and bariatric surgery results in greater FFML than very low caloric diets. Webster et al. [37] was the first to demonstrate that loss in fat-free mass (FFM) should not be more than $22 \%$ of total weight loss because of its function in resting metabolic rate, maintenance of functional capacity as the body ages, thermoregulation, oxidative capacity of the body and weight management.

Exercise training can attenuate muscle atrophy or can even maintain FFM during weight loss in diet studies [35,36], but the value of a standardized exercise program after bariatric surgery or more specific, after gastric bypass surgery, has not been investigated. We now show that a $3 \mathrm{x} /$ week combined aerobic and resistance exercise program could not prevent the loss in FFM, with no significant differences compared to the untrained patients. However, the decline in FFM seemed less severe (absolute: - $5.4 \mathrm{~kg}$; relative: $22.4 \%$ of total weight loss) and was brought within the acceptable limits as determined by Webster et al.[37]. Interestingly, although exercise training (GB+E) could not prevent FFML, it completely prevented strength loss and even induced a significant increase in dynamic strength of most muscle groups (+ $72 \%$ quadriceps strength, $+27 \%$ hamstrings strength and a tendency of $+12 \%$ biceps strength) (table 3 ). The apparent discrepancy between a decline in FFM and an increase in strength in the $\mathrm{GB}+\mathrm{E}$ group can mainly be attributed to the accepted feature that during the early stages of a training program neurological factors have the greatest contribution in the increase in muscle strength [38].

Besides dynamic muscle strength we also measured peripheral static muscle strength by a handgrip strength test (HGS). Surprisingly, peripheral static muscle strength evolved differently compared to 
dynamic muscle strength. There was an overall time effect in the decrease of HGS, meaning that the untrained (GB) as well as the trained patients $(\mathrm{GB}+\mathrm{E})$ lost HGS four months after gastric bypass surgery (GB: $-18 \%$, GB+E: $-7 \%$ ). Probably, training specificity can give an explanation. In our study no static muscle strength exercises were included in the training program and it is known that the exercise must be specific to the type of strength required [38].

In general we can debate about the question 'is a decrease in muscle strength a problem for morbidly obese patients after weight loss?'. It is known that obese patients have higher absolute muscle strength compared to lean subjects, but they have lower relative muscle strength (in terms of total body weight) [19,39-41]. The latter gives the patients an impaired functional capacity, meaning that more strength is necessary to handle their heavier body. Although morbidly obese patients lose weight after bariatric surgery, they often remain, relatively speaking, less strong. Therefore it seems important to prevent a decrease in muscle strength after bariatric surgery.

\section{FUNCTIONAL CAPACITY}

Muscle strength and muscle mass are important in functional capacity. In our study, we subjected the patients to two functional exercises. With regard to our first test, the sit-to-stand (STS) test, the trained patients $(\mathrm{GB}+\mathrm{E})$ improved their number of times to rise to a full stand from a seated position within 30 seconds, whereas the untrained patients (GB) did not. According to literature quadriceps strength and $\%$ body fat mainly determines the sit-to-stand test $[42,43]$.This is in line with our results, where 'GB+E' has $72 \%$ increase in quadriceps muscle strength, where 'GB' has a decrease of $16 \%$.

Percentage body fat could not further explain the difference in STS between the two groups, because both groups lost the same amount of body fat.

The six-minute walking distance (6MWD) is the only test where both the trained and the untrained patients improved. However, further analyzes showed us that the increase is mainly attributed to the increase in ' $\mathrm{GB}+\mathrm{E}$ '. It is known that walking distance is reduced in obese patients compared to lean subjects [44]. According to Tompkins $\mathrm{J}$ et al. [22], bariatric surgery leads to an improvement up to $75 \%$ of normative values six months after the operation. Indeed, weight loss (especially $\%$ body fat) makes walking less exhausting, which can be noticed in our results by a decreased rating of perceived exertion and heart frequency at the end of the test. Not only percentage body fat, but maximal oxygen 
uptake $\left(\mathrm{VO}_{2} \max \right)$ and quadriceps muscle strength are important predictors as well in the 6MWD [4446]. As the first two parameters evolved equally in both groups, quadriceps muscle strength is likely responsible for the more pronounced increase in 6MWD for the trained patients.

\section{EXERCISE CAPACITY AND OXIDATIVE CAPACITY}

Aerobic capacity can be evaluated by a maximal incremental bicycle ergometer test, where the anaerobic threshold (AT) reflects true aerobic capacity and where maximal oxygen uptake $\left(\mathrm{VO}_{2}\right.$ peak $)$ reflects exercise capacity (maximal aerobic capacity).

$\mathrm{VO}_{2}$ peak $(\mathrm{ml} / \mathrm{min}$ ), as well as other peak exercise capacity parameters (peak work, peak heart rate and peak RER) did not change four months after the operation and there were no differences between the untrained and trained patients. To interpret these results, we must know that literature about the effect of weight loss on peak exercise capacity parameters in obese patients is equivocal. Depending on the presence of obesity related disorders, peak exercise capacity will evolve differently. Healthy obese subjects undergoing weigth loss will likely experience a decrease in VO2max and peak work output, because of a decreased muscle mass [47] and because the daily elevated cardiac stress, which is a training for the heart, fades away [48]. In contrast, many obese patients struggle with obesity related disorders such as, impaired cardiac function (impaired left ventricular function and diastolic indices) [49,50], inefficient ventilatory work (added mass on the chest wall and increased pressure in the abdomen) [51] and decreased intramyocellular lipid oxidation [25,52], which are associated with reduced exercise capacity. During weight loss, cardiac and pulmonary systems will restore and will probably overwhelm the negative effect of a decreased muscle mass. This balance can result in a stabilization or even an improvement in maximal oxygen uptake [50].

To neutralize the effect of body weight and fat-free mass, $\mathrm{VO}_{2}$ divided by respectively body weight and FFM, is frequently used. Peak $\mathrm{VO}_{2} / \mathrm{kg} \mathrm{BW}$ improved in both trained and untrained patients and can be explained by an improved body composition (decreased \%FM and increased \%FFM).

Surprisingly, peak $\mathrm{VO}_{2} / \mathrm{kg}$ FFM did not change, meaning that neither weight loss, nor added exercise training could improve the ability of fat-free mass to take up oxygen 4 months after surgery.

With regard to peak power output, the trained patients $(\mathrm{GB}+\mathrm{E})$ could produce more work relative to body weight, whereas the control group (GB) remained unchanged. We assume that 'GB+E' could 
clear the effect of a decreased muscle mass by a more efficient energy expenditure during cycling and a better use of cardiac reserve [48].

While maximal oxygen uptake is equally determined by the oxygen transport system (pulmonary, cardiac and vascular system) and the oxidative capacity of the skeletal muscle (O2 use in the mitochondria), the anaerobic threshold (AT) is mostly determined by the latter (if no severe complications of the first are detected). In our study several measurements at VAT indicate that aerobic capacity does not improve 4 months after bariatric surgery. However, it is possible to elicit training effects during large scale weight loss. Power and time of occurrence at VAT evolved positive in ' $\mathrm{GB}+\mathrm{E}$ ' and remained the same for 'GB' (figure 1 and table 3). Further the percentage oxygen uptake at VAT relative to the oxygen uptake at peak $\left(\% \mathrm{VO}_{2}\right.$ at $\mathrm{VAT} / \mathrm{VO}_{2}$ peak) showed an interaction effect between the intervention group and the control group (table 3). It has been reported that weight loss alone can improve metabolic flexibility (increased insulin sensitivity and reduced IMTG accumulation) [52], but recent diet studies showed that only weight loss combined with exercise can improve aerobic capacity, mitochondrial content and electron chain transport activity in skeletal muscle of sedentary obese subjects [27].

\section{Conclusion}

To summarize, we could demonstrate that large scale weight loss through gastric bypass surgery results in a decrease in dynamic and peripheral static muscle strength and no improvement in aerobic capacity. As a consequence, most components of functional capacity did not improve. In contrast a $3 \mathrm{x} /$ week endurance and resistance exercise program could prevent the decrease and even induce an increase in strength in most muscle groups. Together with an improvement in submaximal aerobic capacity (ventilatory threshold), functional capacity increased significantly. Implementation of an exercise training program in the first 4 months after bariatric surgery is effective and should be promoted. 


\section{ACKNOWLEDGMENTS}

This study was financially supported by a grant from the University Ghent (BOF-project, NR.

01J07007) and by Ethicon Endo-Surgery (A Johnson \& Johnson company). Patients were recruited from the University Hospital Ghent, Belgium (Europe) and from AZ Nikolaas, Sint-Niklaas, Belgium (Europe). 


\section{REFERENCES}

[1] Buchwald H and Williams SE. Bariatric surgery worldwide 2003. Obes Surg 2004; 14: $1157-1164$.

[2] Hedley AA, Ogden CL, Johnson CL et al. Prevalence of overweight and obesity among US children, adolescents, and adults, 1999-2002. JAMA 2004; 291: 2847-2850.

[3] Bult MJ, van DT, Muller AF. Surgical treatment of obesity. Eur J Endocrinol 2008; 158: $135-145$.

[4] Elder KA and Wolfe BM. Bariatric surgery: a review of procedures and outcomes. Gastroenterology 2007; 132: 2253-2271.

[5] Farrell TM, Haggerty SP, Overby DW et al. Clinical application of laparoscopic bariatric surgery: an evidence-based review. Surg Endosc 2009;

[6] Must A, Spadano J, Coakley EH et al. The disease burden associated with overweight and obesity. JAMA 1999; 282: 1523-1529.

[7] Bray GA. Medical consequences of obesity. J Clin Endocrinol Metab 2004; 89: 25832589.

[8] Overweight, obesity, and health risk. National Task Force on the Prevention and Treatment of Obesity. Arch Intern Med 2000; 160: 898-904.

[9] Kral JG and Naslund E. Surgical treatment of obesity. Nat Clin Pract Endocrinol Metab 2007; 3: 574-583. 
[10] Torquati A, Lutfi R, Abumrad N et al. Is Roux-en-Y gastric bypass surgery the most effective treatment for type 2 diabetes mellitus in morbidly obese patients? J Gastrointest Surg 2005; 9: 1112-1116.

[11] Clements RH, Gonzalez QH, Long CI et al. Hormonal changes after Roux-en Y gastric bypass for morbid obesity and the control of type-II diabetes mellitus. Am Surg 2004; 70: $1-4$.

[12] Pietilainen KH, Kaprio J, Borg P et al. Physical inactivity and obesity: a vicious circle. Obesity (Silver Spring) 2008; 16: 409-414.

[13] Telford RD. Low physical activity and obesity: causes of chronic disease or simply predictors? Med Sci Sports Exerc 2007; 39: 1233-1240.

[14] Stefan MA, Hopman WM, Smythe JF. Effect of activity restriction owing to heart disease on obesity. Arch Pediatr Adolesc Med 2005; 159: 477-481.

[15] Carey DG, Pliego GJ, Raymond RL et al. Body composition and metabolic changes following bariatric surgery: effects on fat mass, lean mass and basal metabolic rate. Obes Surg 2006; 16: 469-477.

[16] Poitou BC, Ciangura C, Coupaye M et al. Nutritional deficiency after gastric bypass: diagnosis, prevention and treatment. Diabetes Metab 2007; 33: 13-24.

[17] Brown M, Sinacore DR, Host HH. The relationship of strength to function in the older adult. J Gerontol A Biol Sci Med Sci 1995; 50 Spec No: 55-59.

[18] Wolfson L, Judge J, Whipple R et al. Strength is a major factor in balance, gait, and the occurrence of falls. J Gerontol A Biol Sci Med Sci 1995; 50 Spec No: 64-67. 
[19] Maffiuletti NA, Jubeau M, Munzinger U et al. Differences in quadriceps muscle strength and fatigue between lean and obese subjects. Eur J Appl Physiol 2007; 101: 5159.

[20] Maffiuletti NA, Jubeau M, Agosti F et al. Quadriceps muscle function characteristics in severely obese and nonobese adolescents. Eur J Appl Physiol 2008;

[21] Maniscalco M, Zedda A, Giardiello C et al. Effect of bariatric surgery on the six-minute walk test in severe uncomplicated obesity. Obes Surg 2006; 16: 836-841.

[22] Tompkins J, Bosch PR, Chenowith R et al. Changes in functional walking distance and health-related quality of life after gastric bypass surgery. Phys Ther 2008; 88: 928-935.

[23] Mathier MA and Ramanathan RC. Impact of obesity and bariatric surgery on cardiovascular disease. Med Clin North Am 2007; 91: 415-4xi.

[24] He J, Watkins S, Kelley DE. Skeletal muscle lipid content and oxidative enzyme activity in relation to muscle fiber type in type 2 diabetes and obesity. Diabetes 2001; 50: $817-823$.

[25] Houmard JA. Intramuscular lipid oxidation and obesity. Am J Physiol Regul Integr Comp Physiol 2008; 294: R1111-R1116.

[26] Kelley DE. Skeletal muscle fat oxidation: timing and flexibility are everything. J Clin Invest 2005; 115: 1699-1702.

[27] Toledo FG, Menshikova EV, Azuma K et al. Mitochondrial capacity in skeletal muscle is not stimulated by weight loss despite increases in insulin action and decreases in intramyocellular lipid content. Diabetes 2008; 57: 987-994. 
[28] Tanner CJ, Barakat HA, Dohm GL et al. Muscle fiber type is associated with obesity and weight loss. Am J Physiol Endocrinol Metab 2002; 282: E1191-E1196.

[29] Rice B, Janssen I, Hudson R et al. Effects of aerobic or resistance exercise and/or diet on glucose tolerance and plasma insulin levels in obese men. Diabetes Care 1999; 22: 684-691.

[30] Janssen I, Fortier A, Hudson R et al. Effects of an energy-restrictive diet with or without exercise on abdominal fat, intermuscular fat, and metabolic risk factors in obese women. Diabetes Care 2002; 25: 431-438.

[31] Kushner RF and Schoeller DA. Estimation of total body water by bioelectrical impedance analysis. Am J Clin Nutr 1986; 44: 417-424.

[32] Pace HV and Rathbun EN. Studies on body composition, body water and chemically combined nitrogen content in relation to fat content. J Biol Chem 2009; 158: 685-691.

[33] Enright PL. The six-minute walk test. Respir Care 2003; 48: 783-785.

[34] Wasserman K, Whipp BJ, Koyl SN et al. Anaerobic threshold and respiratory gas exchange during exercise. J Appl Physiol 1973; 35: 236-243.

[35] Stiegler P and Cunliffe A. The role of diet and exercise for the maintenance of fat-free mass and resting metabolic rate during weight loss. Sports Med 2006; 36: 239-262.

[36] Chaston TB, Dixon JB, O'Brien PE. Changes in fat-free mass during significant weight loss: a systematic review. Int J Obes (Lond) 2007; 31: 743-750.

[37] Webster JD, Hesp R, Garrow JS. The composition of excess weight in obese women estimated by body density, total body water and total body potassium. Hum Nutr Clin Nutr 1984; 38: 299-306. 
[38] Folland JP and Williams AG. The adaptations to strength training : morphological and neurological contributions to increased strength. Sports Med 2007; 37: 145-168.

[39] Blimkie CJ, Sale DG, Bar-Or O. Voluntary strength, evoked twitch contractile properties and motor unit activation of knee extensors in obese and non-obese adolescent males. Eur J Appl Physiol Occup Physiol 1990; 61: 313-318.

[40] Pescatello LS, Kelsey BK, Price TB et al. The muscle strength and size response to upper arm, unilateral resistance training among adults who are overweight and obese. $\mathbf{J}$ Strength Cond Res 2007; 21: 307-313.

[41] Hulens M, Vansant G, Lysens R et al. Study of differences in peripheral muscle strength of lean versus obese women: an allometric approach. Int J Obes Relat Metab Disord 2001; 25: 676-681.

[42] Bohannon RW. Body weight-normalized knee extension strength explains sit-to-stand independence: a validation study. J Strength Cond Res 2009; 23: 309-311.

[43] Bohannon RW. Knee extension strength and body weight determine sit-to-stand independence after stroke. J Strength Cond Res 2007; 23: 309-311.

[44] Hulens M, Vansant G, Claessens AL et al. Predictors of 6-minute walk test results in lean, obese and morbidly obese women. Scand J Med Sci Sports 2003; 13: 98-105.

[45] Laukkanen R, Oja P, Pasanen M et al. Validity of a two kilometre walking test for estimating maximal aerobic power in overweight adults. Int J Obes Relat Metab Disord 1992; 16: 263-268.

[46] Mattsson E, Larsson UE, Rossner S. Is walking for exercise too exhausting for obese women? Int J Obes Relat Metab Disord 1997; 21: 380-386. 
[47] Goran M, Fields DA, Hunter GR et al. Total body fat does not influence maximal aerobic capacity. Int J Obes Relat Metab Disord 2000; 24: 841-848.

[48] Seres L, Lopez-Ayerbe J, Coll R et al. Increased exercise capacity after surgically induced weight loss in morbid obesity. Obesity (Silver Spring) 2006; 14: 273-279.

[49] Carroll S, Marshall P, Borkoles E et al. Efficacy of lifestyle intervention on peak exercise cardiac power output and reserve in premenopausal obese females: a randomised pilot study. Int J Cardiol 2007; 119: 147-155.

[50] Kanoupakis E, Michaloudis D, Fraidakis O et al. Left ventricular function and cardiopulmonary performance following surgical treatment of morbid obesity. Obes Surg 2001; 11: 552-558.

[51] GILBERT R, SIPPLE JH, AUCHINCLOSS JH, Jr. Respiratory control and work of breathing in obese subjects. J Appl Physiol 1961; 16: 21-26.

[52] Corpeleijn E, Saris WH, Blaak EE. Metabolic flexibility in the development of insulin resistance and type 2 diabetes: effects of lifestyle. Obes Rev 2009; 10: 178-193. 


\section{TABLES}

Table 1: Pre-operative characteristics of the study groups (GB and GB $+\mathrm{E})$.

\begin{tabular}{|l|l|l|}
\hline & $\begin{array}{l}\text { Gastric bypass without exercise } \\
(\mathrm{GB})\end{array}$ & $\begin{array}{l}\text { Gastric Bypass with exercise } \\
(\mathrm{GB}+\mathrm{E})\end{array}$ \\
\hline Number $(\mathrm{n})$ & 7 & 8 \\
\hline Age $($ years $)$ & $43,1( \pm 5,6)$ & $39,9( \pm 9,9)$ \\
\hline Gender male/female $(\mathrm{n})$ & $3 / 4$ & $1 / 7$ \\
\hline BMI $(\mathrm{kg} / \mathrm{m} 2)$ & $40,4( \pm 8,1)$ & $45,3( \pm 2,7)$ \\
\hline Operation & $\begin{array}{l}7 \text { gastric bypass } \\
\text { (of which 2 conversions) }\end{array}$ & $\begin{array}{l}\text { 8 gastric bypass } \\
\text { (of which 2 conversions) }\end{array}$ \\
\hline Data are presented as nor means $\pm \mathrm{SD}$.
\end{tabular}


Table 2: Absolute and relative changes in anthropometrical characteristics and body composition 4 months after gastric bypass. Comparison GB and GB+E.

\begin{tabular}{|c|c|c|c|c|c|c|}
\hline & & $\begin{array}{l}\text { PRE- } \\
\text { operative } \\
\text { values }\end{array}$ & $\begin{array}{l}\text { Absolute } \\
\text { decrease }\end{array}$ & $\begin{array}{l}\text { Relative } \\
\text { decrease }(\%)\end{array}$ & $\begin{array}{c}\text { Time } \\
\text { (p-value) }\end{array}$ & $\begin{array}{c}\text { Interaction } \\
\text { (p-value) }\end{array}$ \\
\hline Weight $(\mathrm{kg})$ & $\begin{array}{l}\text { GB } \\
\text { GB+E }\end{array}$ & $\begin{array}{l}126,5( \pm 24,7) \\
130,8( \pm 17,8)\end{array}$ & $\begin{array}{l}-26,6( \pm 14,6) \\
-22,7( \pm 5,7)\end{array}$ & $\begin{array}{l}-20,1( \pm 8,7) \\
-17,9( \pm 5,8)\end{array}$ & $\mathrm{p}<0,001$ & 0,511 \\
\hline BMI $\left(\mathrm{kg} / \mathrm{m}^{2}\right)$ & $\begin{array}{l}\mathrm{GB} \\
\mathrm{GB}+\mathrm{E}\end{array}$ & $\begin{array}{l}40,4( \pm 8,1) \\
45,3( \pm 2,7)\end{array}$ & $\begin{array}{l}-8,3( \pm 4,1) \\
-8,1( \pm 2,5)\end{array}$ & $\begin{array}{l}-20,1( \pm 8,7) \\
-17,9( \pm 5,8)\end{array}$ & $\mathrm{p}<0,001$ & 0,889 \\
\hline Waist $(\mathrm{cm})$ & $\begin{array}{l}\mathrm{GB} \\
\mathrm{GB}+\mathrm{E}\end{array}$ & $\begin{array}{l}129,7( \pm 20,1) \\
139,4( \pm 11,8)\end{array}$ & $\begin{array}{l}-20,3( \pm 11,6) \\
-17,2( \pm 8,1)\end{array}$ & $\begin{array}{l}-15,3( \pm 8,3) \\
-12,3( \pm 5,7)\end{array}$ & $\mathrm{p}<0,001$ & 0,555 \\
\hline FFM (kg) & $\begin{array}{l}\text { GB } \\
\mathrm{GB}+\mathrm{E}\end{array}$ & $\begin{array}{l}69,0( \pm 13,5) \\
63,9( \pm 14,2) \\
\end{array}$ & $\begin{array}{l}-7,6( \pm 4,7) \\
-5,4( \pm 2,6)\end{array}$ & $\begin{array}{l}-10,5( \pm 4,6) \\
-8,5( \pm 4,3)\end{array}$ & $\mathrm{p}<0,001$ & 0,299 \\
\hline$\underline{\mathrm{FM}}(\mathrm{kg})$ & $\begin{array}{l}\mathrm{GB} \\
\mathrm{GB}+\mathrm{E}\end{array}$ & $\begin{array}{c}57,5( \pm 14,0) \\
66,7( \pm 9,0)\end{array}$ & $\begin{array}{c}-19,0( \pm 10,2) \\
-17,3( \pm 4,6)\end{array}$ & $\begin{array}{l}-32,1( \pm 15,1) \\
-26,8( \pm 9,8)\end{array}$ & $\mathrm{p}<0,001$ & 0,689 \\
\hline$\%$ FFML & $\begin{array}{l}\mathrm{GB} \\
\mathrm{GB}+\mathrm{E}\end{array}$ & $\begin{array}{l}1 \\
1\end{array}$ & $\begin{array}{l}1 \\
1\end{array}$ & $\begin{array}{l}-29,7( \pm 8,2) \\
-22,4( \pm 10,1)\end{array}$ & \multicolumn{2}{|c|}{$\frac{\text { Indep. T-test (p-value) }}{0,166}$} \\
\hline
\end{tabular}
(FFM) Fat Free Mass and (\%FFML) \%fat-free mass loss of total weight loss.

P-values for overall intervention (exercise program) and time effects are given ( $p<0,05$ level of significance). Data are presented as means \pm SD. 
Table 3: Parameters of physical fitness pre-operative and 4 months post-operative. Comparison GB and $\mathrm{GB}+\mathrm{E}$

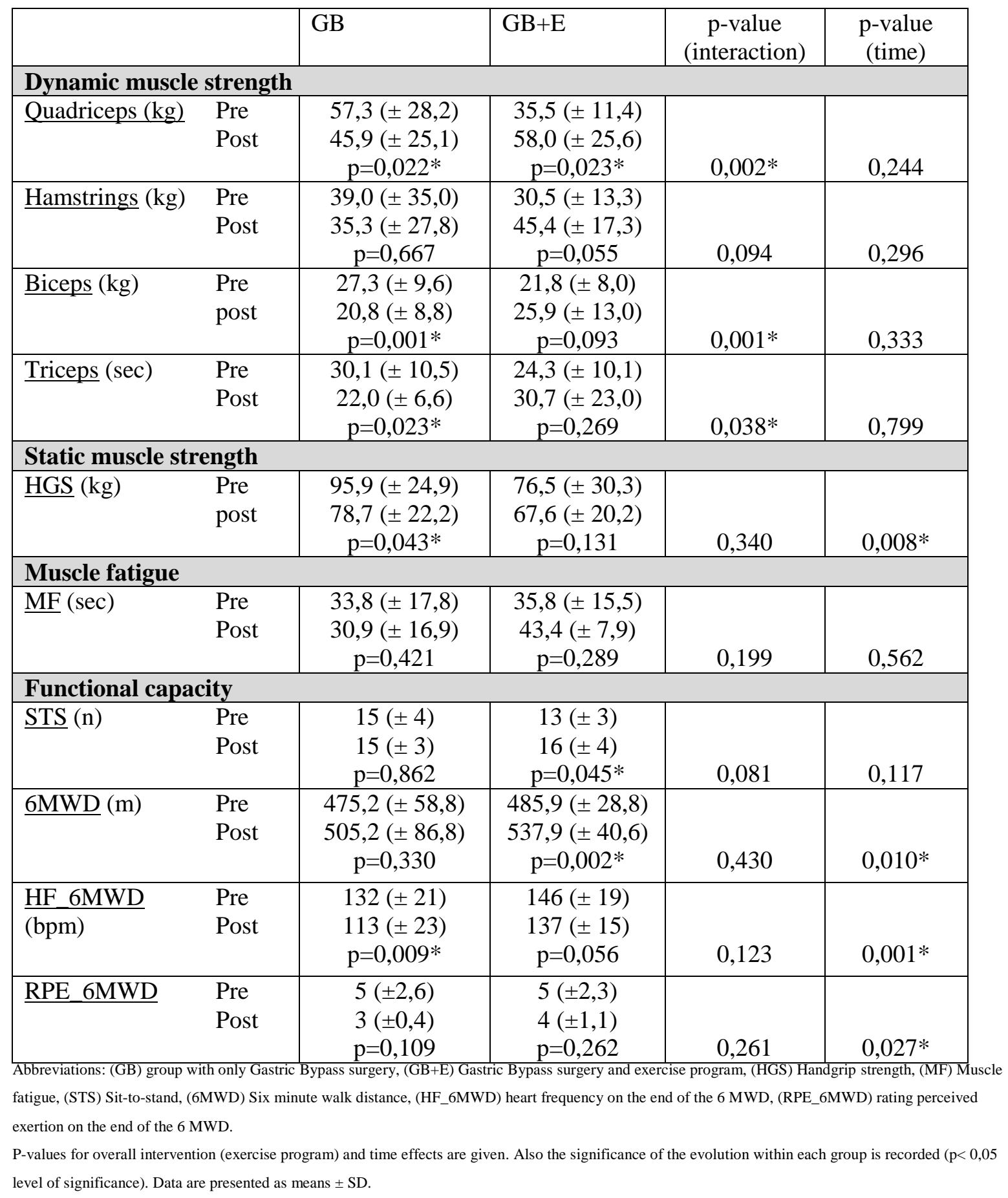


Table 4: Power and oxygen uptake at ventilatory anaerobic threshold derived from the maximal bicycle ergometer test.

\begin{tabular}{|c|c|c|c|c|c|}
\hline \multicolumn{2}{|c|}{ Parameters at Anaerobic threshold } & GB & $\mathrm{GB}+\mathrm{E}$ & $\begin{array}{l}\text { P-value } \\
\text { (Time) }\end{array}$ & $\begin{array}{c}\text { P-value } \\
\text { (interaction) }\end{array}$ \\
\hline Power at VAT (Wattage) & $\begin{array}{l}\text { Pre } \\
\text { Post }\end{array}$ & $\begin{array}{c}93( \pm 24) \\
95( \pm 32) \\
0,695\end{array}$ & $\begin{array}{c}90( \pm 24) \\
111( \pm 40) \\
0,025\end{array}$ & 0,03 & 0,074 \\
\hline$\% \mathrm{VO}_{2}$ at $\mathrm{VAT} / \mathrm{VO}_{2}$ peak & $\begin{array}{l}\text { Pre } \\
\text { Post }\end{array}$ & $\begin{array}{c}69( \pm 11) \\
65( \pm 8) \\
0,305\end{array}$ & $\begin{array}{c}59( \pm 9) \\
65( \pm 5) \\
0,191\end{array}$ & 0,566 & 0,049 \\
\hline
\end{tabular}

$\mathrm{VO} 2$ at VAT/VO2peak) percentage oxygen uptake at the ventilatory anaerobic threshold, relative to the oxygen uptake at peak. P-values for overall intervention (exercise program) and time effects are given. Also the significance of the evolution within each group is recorded ( $\mathrm{p}<0,05$ level of significance). Data are presented as means $\pm \mathrm{SD}$. 
Table 5: Peak exercise capacity parameters of the maximal bicycle ergometer test. Comparison between $\mathrm{GB}$ and $\mathrm{GB}+\mathrm{E}$.

\begin{tabular}{|c|c|c|c|c|}
\hline \multicolumn{2}{|c|}{ Peak exercise capacity parameters } & GB & $\mathrm{GB}+\mathrm{E}$ & $\begin{array}{l}\text { P-value } \\
\text { (Time) }\end{array}$ \\
\hline Peak $\mathrm{VO}_{2}(\mathrm{ml} / \mathrm{min})$ & $\begin{array}{l}\text { Pre } \\
\text { Post }\end{array}$ & $\begin{array}{c}2253( \pm 981) \\
2148( \pm 688) \\
0,634\end{array}$ & $\begin{array}{c}2278( \pm 599) \\
2294( \pm 777) \\
0,915\end{array}$ & 0,729 \\
\hline $\begin{array}{l}\text { Peak } \mathrm{VO}_{2} / \mathrm{kg} \mathrm{BW} \\
(\mathrm{ml} / \mathrm{kg} / \mathrm{min})\end{array}$ & $\begin{array}{l}\text { Pre } \\
\text { Post }\end{array}$ & $\begin{array}{c}17,4( \pm 4,9) \\
21,8( \pm 6,3) \\
0,023\end{array}$ & $\begin{array}{c}17,6( \pm 3,2) \\
22,1( \pm 5,1) \\
0,024\end{array}$ & 0,001 \\
\hline $\begin{array}{l}\text { Peak VO } \mathrm{VO}_{2} / \mathrm{kg} \text { FFM } \\
(\mathrm{ml} / \mathrm{kg} / \mathrm{min})\end{array}$ & $\begin{array}{l}\text { Pre } \\
\text { Post }\end{array}$ & $\begin{array}{c}31,5( \pm 7,8) \\
34,6( \pm 7,9) \\
0,316\end{array}$ & $\begin{array}{c}36,4( \pm 7,2) \\
41,1( \pm 10,9) \\
0,180\end{array}$ & 0,09 \\
\hline Power(W) & $\begin{array}{l}\text { Pre } \\
\text { Post }\end{array}$ & $\begin{array}{c}150( \pm 53) \\
147( \pm 44) \\
0,809 \\
\end{array}$ & $\begin{array}{c}158( \pm 46) \\
168( \pm 63) \\
0,338 \\
\end{array}$ & 0,605 \\
\hline Power/kg BW (W/kg BW) & $\begin{array}{l}\text { Pre } \\
\text { Post }\end{array}$ & $\begin{array}{c}1,26( \pm 0,51) \\
1,48( \pm 0,51) \\
0,143\end{array}$ & $\begin{array}{c}1,20( \pm 0,25) \\
1,54( \pm 0,37) \\
0,002\end{array}$ & 0,002 \\
\hline Heart rate (beats/min) & $\begin{array}{l}\text { Pre } \\
\text { Post }\end{array}$ & $\begin{array}{c}146( \pm 30) \\
156( \pm 17) \\
0,441\end{array}$ & $\begin{array}{c}164( \pm 17) \\
157( \pm 14) \\
0,037\end{array}$ & 0,742 \\
\hline RER & $\begin{array}{l}\text { Pre } \\
\text { Post }\end{array}$ & $\begin{array}{c}1,13( \pm 0,14) \\
1,14( \pm 0,06) \\
0,364\end{array}$ & $\begin{array}{c}1,11( \pm 0,12) \\
1,10( \pm 0,07) \\
0,832\end{array}$ & 0,342 \\
\hline
\end{tabular}

Abbreviations: (GB) group with only Gastric Bypass surgery, (GB+E) Gastric Bypass surgery and exercise program, (Peak VO2) peak oxygen uptake, (Peak VO2/kg BW) peak oxygen uptake relative to body weight, (Peak VO2/kg FFM) peak oxygen uptake relative to fat-free mass, (Power/kg BW) Power output relative to body weight, RER (respiratory exchange ratio).

No interaction effects were recorded. P-values for overall time effects are given. Also the significance of the evolution within each group is recorded ( $\mathrm{p}<0,05$ level of significance). Data are presented as means $\pm \mathrm{SD}$. 
Figure 1: Time of occurrence (seconds) of Ventilatory Anaerobic Threshold (VAT) during the maximal bicycle ergometer test. Comparison between GB and GB+E.

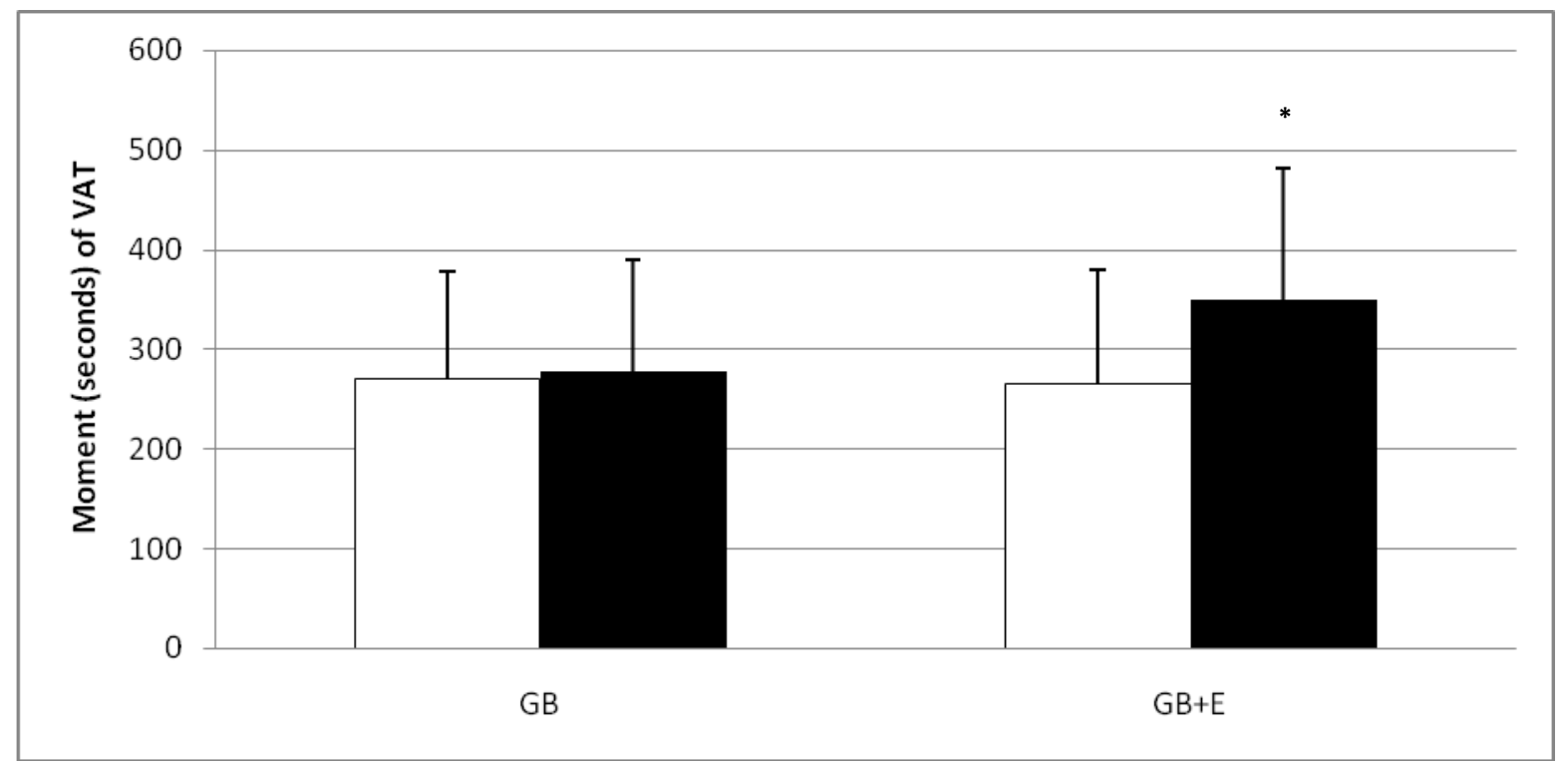

Abbreviations: (GB) group with only Gastric Bypass surgery, (GB+E) Gastric Bypass surgery and exercise program. $\square$ pre-operative, $\square$ post-operative. * $p<$ 0,05 versus pre-operatively. 